\title{
Serum Level of Helicobacter pylori Antibody in Stroke Patients
}

\author{
Shahir Mazaheri', Mojtaba Khazaei ${ }^{2}$,* iD , Abbas Moradi ${ }^{3}$, Reza Raei ${ }^{4}$ \\ ${ }^{I}$ Associate Professor, Department of Neurology, School of Medicine, Hamadan University of Medical Sciences, Hamadan, \\ Iran \\ ${ }^{2}$ Assistant Professor, Department of Neurology, School of Medicine, Hamadan University of Medical Sciences, Hamadan, \\ Iran \\ ${ }^{3}$ Academic Member, Department of Community Medicine, School of Medicine, Hamadan University of Medical Sciences, \\ Hamadan, Iran \\ ${ }^{4}$ General Practitioner, Hamadan University of Medical Sciences, Hamadan, Iran \\ * Corresponding Author: Mojtaba Khazaei, Department of Neurology, School of Medicine, Hamadan University of Medical \\ Sciences, Hamadan, Iran.Email: khazaeimojtaba@yahoo.com
}

\begin{tabular}{|c|c|}
\hline & Abstract \\
\hline $\begin{array}{l}\text { Received: } 06.10 .2019 \\
\text { Accepted: } 22.01 .2020\end{array}$ & \multirow[b]{2}{*}{$\begin{array}{l}\text { Background and Objective: Stroke is the third most common cause of } \\
\text { death in developed countries and the most common disabling neurological } \\
\text { disease. There are several risk factors for stroke. Regarding this, the present } \\
\text { study was conducted to investigate the effect of Helicobacter pylori antibody } \\
\text { on the incidence of stroke. } \\
\text { Materials and Methods: This case-control study was conducted on } 50 \\
\text { patients (i.e., case group) with stroke admitted to Sina Teaching Hospital of } \\
\text { Hamadan, Iran, using convenience sampling method. This group was } \\
\text { compared with } 50 \text { healthy controls in terms of the serum level of } \\
\text { Helicobacter pylori antibody. The data were analyzed using SPSS software } \\
\text { (version } 21 \text { ) using proper statistical tests at } 95 \% \text { confidence interval. } \\
\text { Results: The mean serum levels of Helicobacter pylori antibody in the case } \\
\text { and control groups were } 25.93 \pm 44.03 \text { and } 35.36 \pm 41.25 \text { Uarb/ml, } \\
\text { respectively (P=0.108). In addition, the serum levels of this antibody were } \\
\text { obtained as } 20.78 \text { and } 35.84 \text { (P=0.055) in the females and } 31.51 \text { and } 34.31 \\
\text { (P=0.501) in the males of the control and case groups, respectively. The } \\
\text { Spearman correlation coefficient revealed a positive but insignificant } \\
\text { relationship between age and serum antibody level of Helicobacter pylori in } \\
\text { both groups ( } \mathrm{r}=0.150 ; \mathrm{P}=0.13 \text { ). } \\
\text { Conclusion: As the findings indicated, the stroke patients had a lower serum } \\
\text { level of Helicobacter pylori antibody, compared to the healthy non-stroke } \\
\text { patients; however, this difference was not statistically significant. }\end{array}$} \\
\hline $\begin{array}{l}\text { How to Cite this Article: } \\
\text { Mazaheri S, Khazaei M, Moradi } \\
\text { A, Raei R. Serum Level of } \\
\text { Helicobacter pylori Antibody in } \\
\text { Stroke Patients. Avicenna J Clin } \\
\text { Med. 2020; 26(4): 206-212. } \\
\text { DOI: } 10.29252 / \text { ajcm.26.4.206 }\end{array}$ & \\
\hline & \\
\hline
\end{tabular}


doI: $10.29252 / \mathrm{ajcm} \cdot 26.4 .206$

\title{
بررسى سطح سرمى آنتىبادى هليكوباكتر ييلورى در بيماران مبتلا به استروك
}

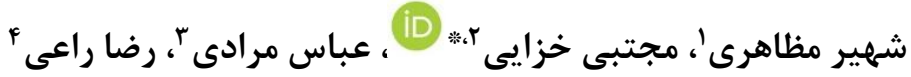

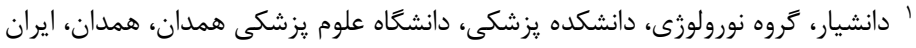

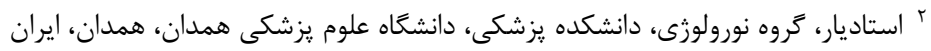

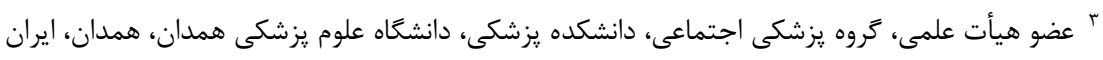

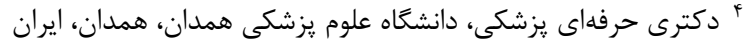

* نويسنده مسئول: مجتبى خزايى، كروه نورولوزى، دانشكده يزشكى، دانشكاه علوم يزشكى همدان، همدان، ايران. ايميل: khazaeimojtaba@yahoo.com

\begin{tabular}{|c|c|}
\hline 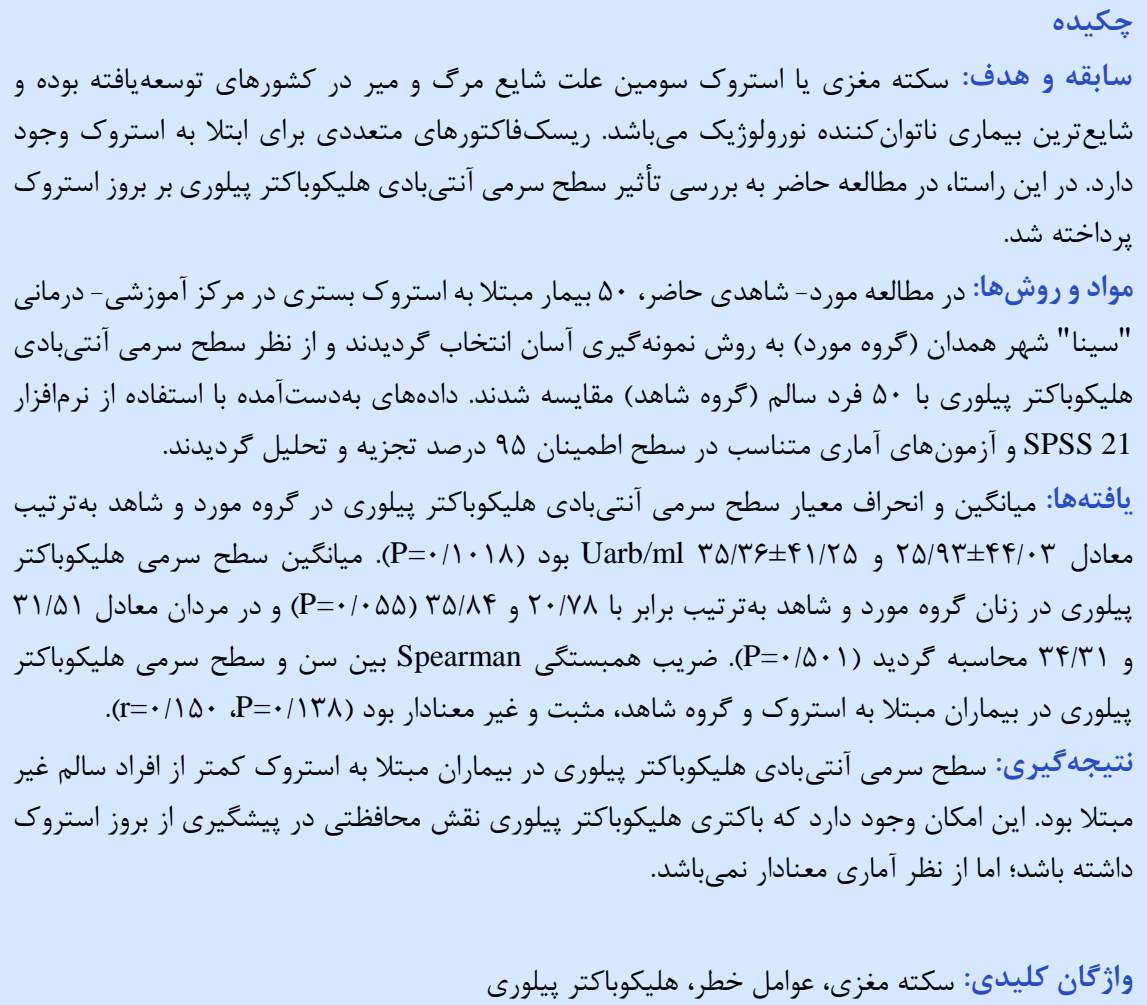 & 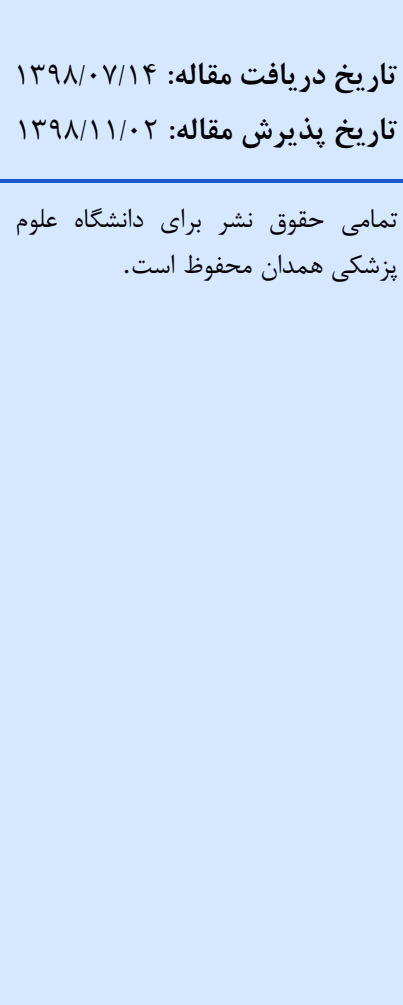 \\
\hline
\end{tabular}

مرگ و مير در جهان يس از سكتههاى قلبى و سرطانها مطرح

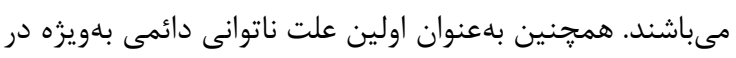

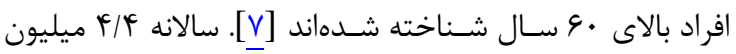

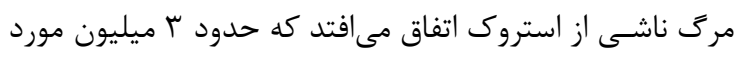

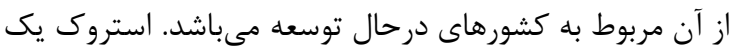

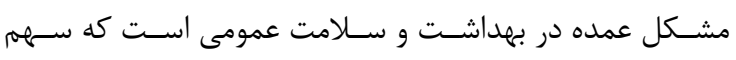

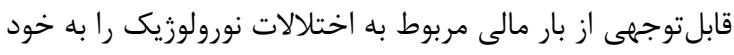

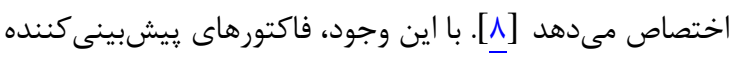

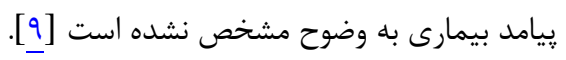

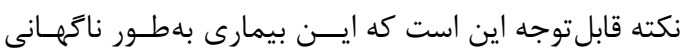

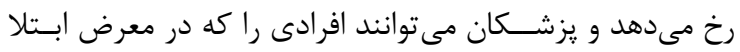

سـكته مغزى يا اسـتروك يك تشـخيص بالينى اســت كه

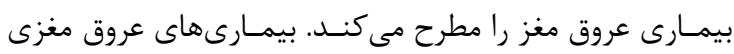

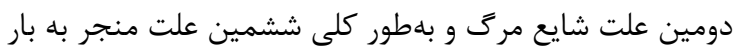

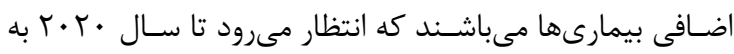
رده جهارم برسند [1].

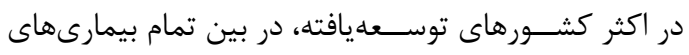

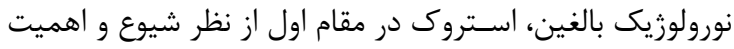

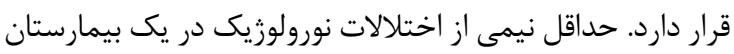

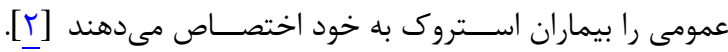

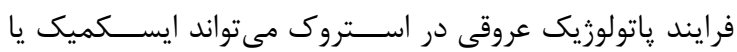

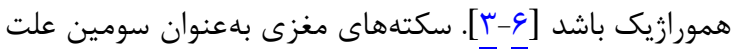


بيمـارى عروق كوجـــ وجود نــارد و ابتلا بــه اين عفونست

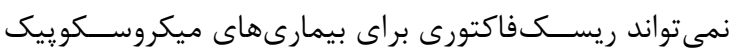

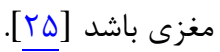

همجنين سـاكًار و همكاران در يزوهشى كه در كشور هند

انجام دادند، فرضسيه ارتباط بين عفونت با هليكوباكتر و سكته

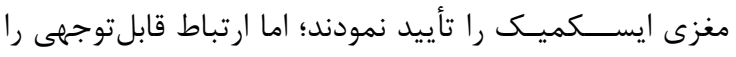

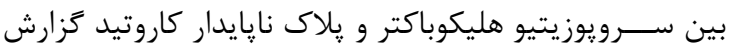

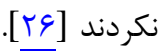

مطالعهاى نيز توسط يِيترويوسـتى و همكاران با موضـوع

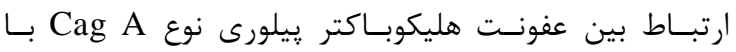
سـكته هاى مغزى آترواسـكلروتيك در كشور ايتاليا انجام شد.

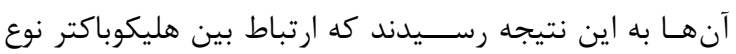

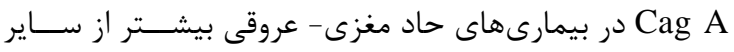
كروهها مى باشد [rV]

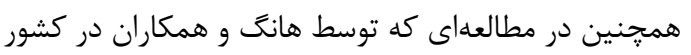
جين انجام شد، محققان به اين نتيجه رسيدند كه كهاب ابتلاى مزمن

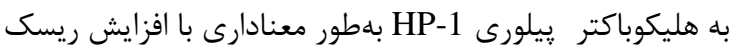
اسـتروك ايسـميك بهويزه نوع غير آمبوليك آن ارتباط دارد و

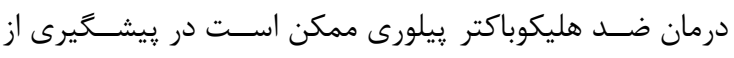

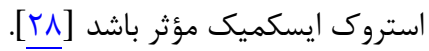

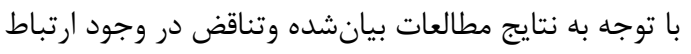

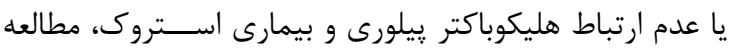

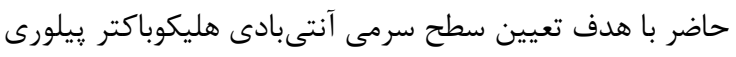

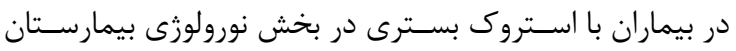
فرشجيان (سينا) همدان انجام شد.

\section{مواد و روشها}

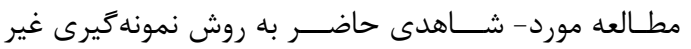

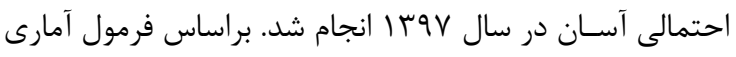

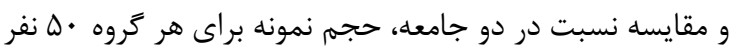

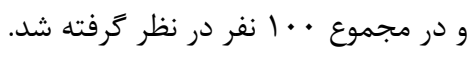

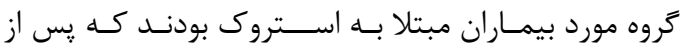

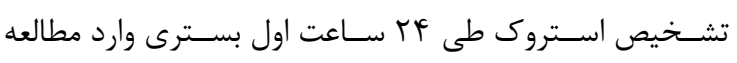

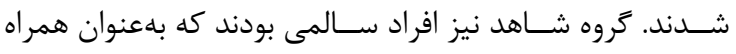

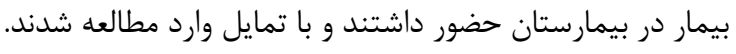

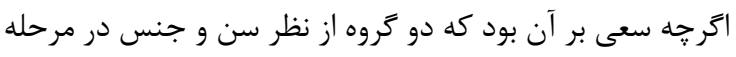

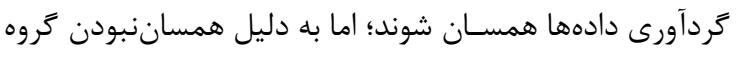

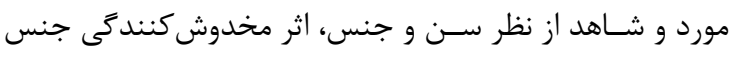

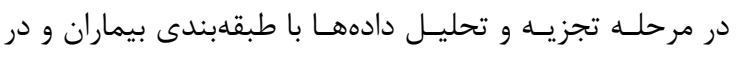

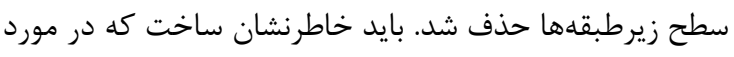

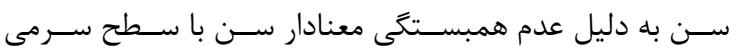

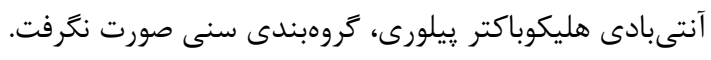

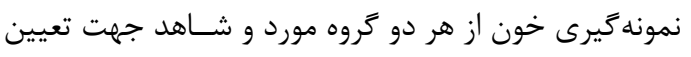

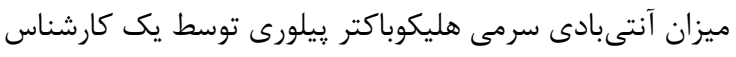

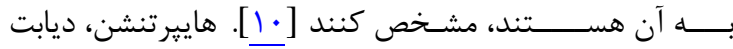

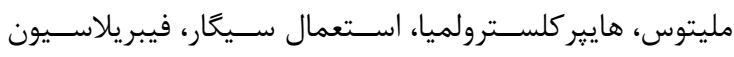

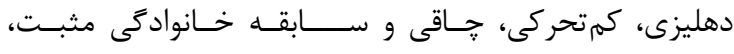

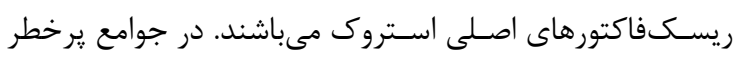

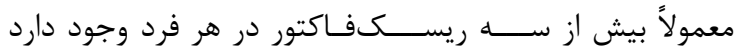

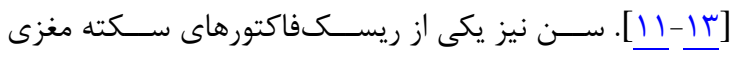

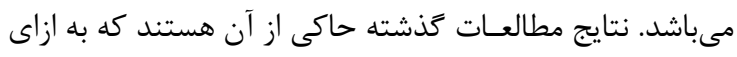

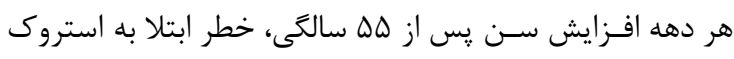
دو برابر مىشود [1F]

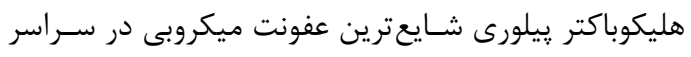

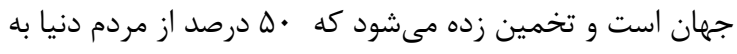

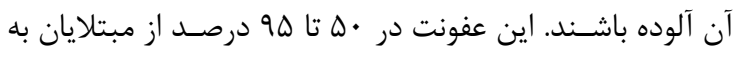

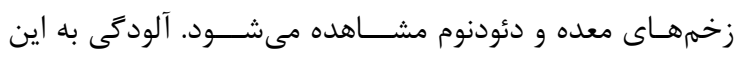

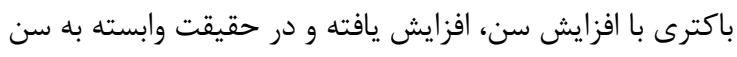

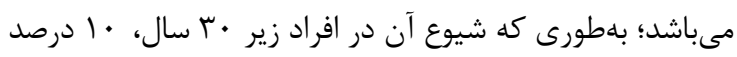

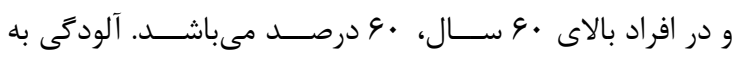

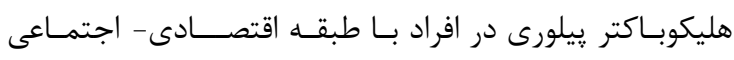

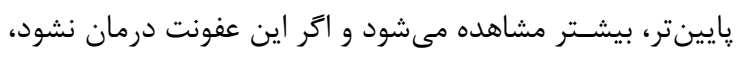

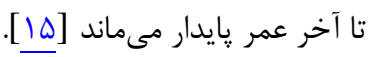

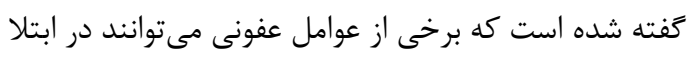

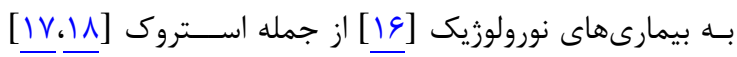

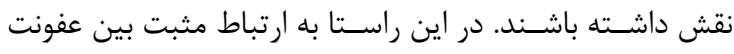

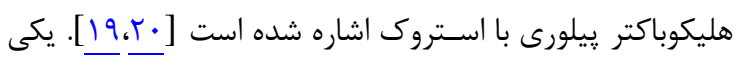

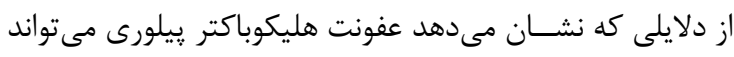

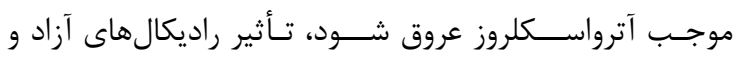

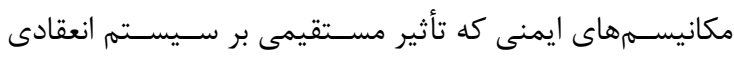

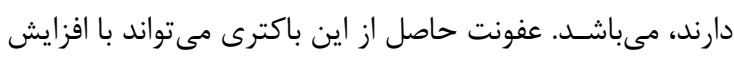

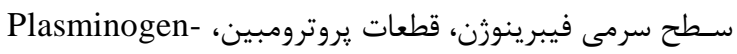
activating Inhibitor-1 ايجاد كند. ارتباط ديخرى كه متصـــور اســــ، احتمالاً به دنبال

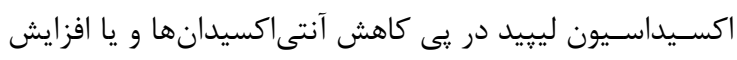

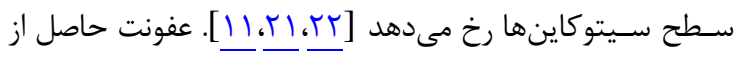

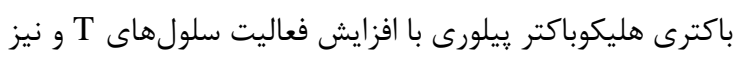

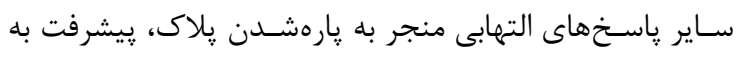

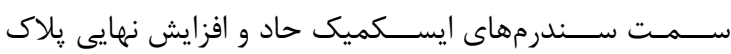

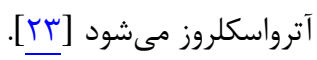

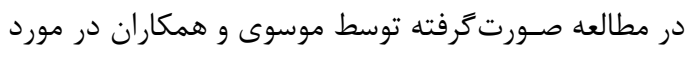

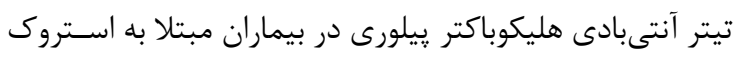

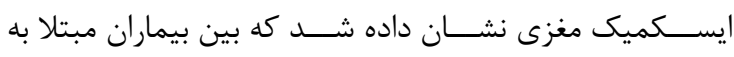

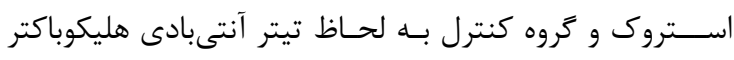

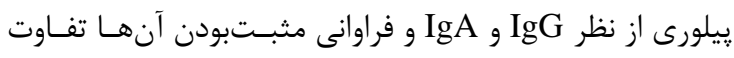
آمارى معنادارى وجود ندارد [Tr]

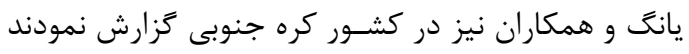

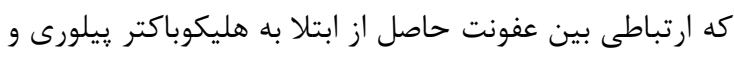


يرسشنامهها پس از تكميل در نرمافزار 16 SPSS ثبت

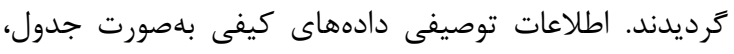

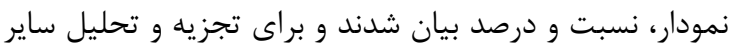

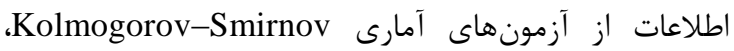
Spearman تحليلها در سطح اطمينان هو درصد صورت گرفت و و سطح

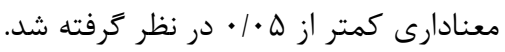

\section{يافتهها}

در اين مطالعه •له بيمار مبتلا به اسـتروك با • له فرد سالم

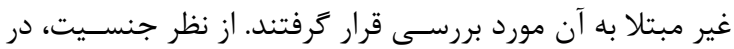

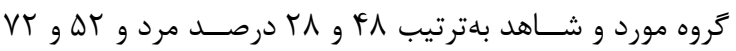

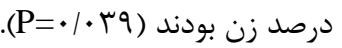

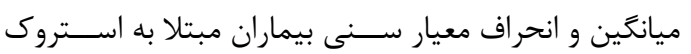

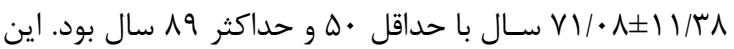

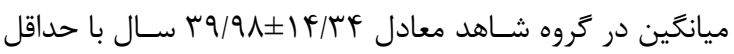

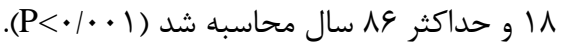

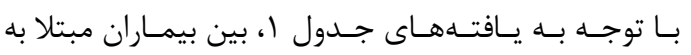

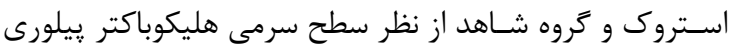
تفاوت آمارى معنادارى وجود نداشت.

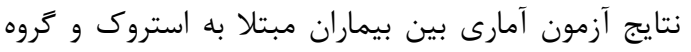

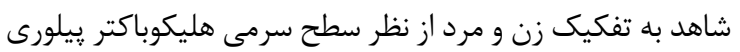

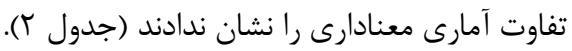

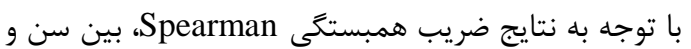

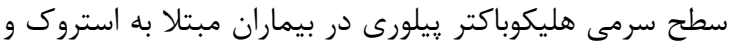

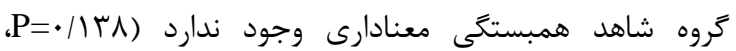
. $(r=-\cdot / 1) \omega$.
يرستارى صورت گرفت و پس از سانتريفيوز، سرم آنها جدا شد

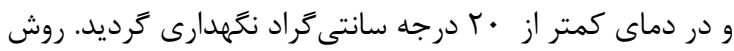

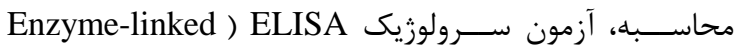
(Immunosorbent Assay

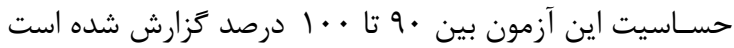
[rY.rQ.r.] در اين مطالعه از كيت Italy) Equipar) استفاده شد. واحد سنجش اين كيت Uarb/ml است. كليه مراحل آزمايش براساس دستورالعمل كيت انجام شد.

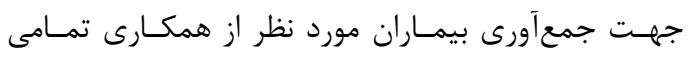

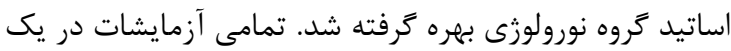

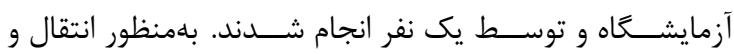

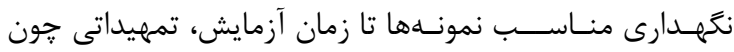

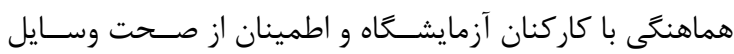

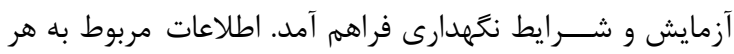

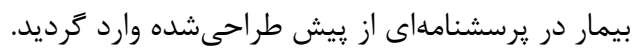
معيارهاى ورود به مطالعه عبارت بودند از: تشـخيص استروك در F T ساعت اول بيمارى، رضايت بيمار يا فرد شاهد جهت شركت در مطالعه، نداشتن سابقه قبلى سكته

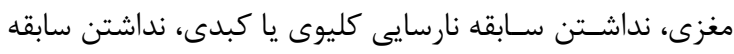

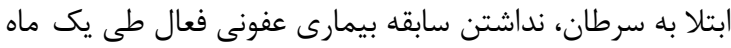

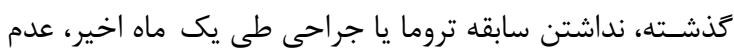

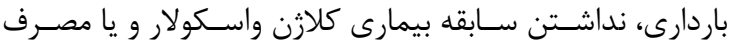

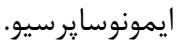
عدم مراجعه براى انجام آزمايشات لازم، عدم مراجعه مجدد

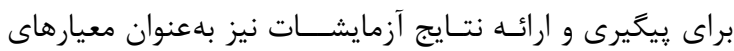
خروج در نظر كرفته شدند.

جدول ا: ميانكَين و انحراف معيار سطح سرمى آنتىبادى هليكوباكتر ييلورى در دو گروه مورد و شاهد

\begin{tabular}{|c|c|c|c|}
\hline سطح معنادارى" & كروه & 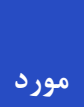 & سطح سرمى هليكوباكتر بيلورى (Uarb/ml) \\
\hline \multirow{5}{*}{$\cdot 11 \cdot 1$} & $r \Delta / r \varphi$ & $r \Delta / q r$ & ميانگين \\
\hline & $F I / r \Delta$ & $r F / \cdot r$ & انحراف معيار \\
\hline & $V / F$. & $\Delta / V \cdot$ & 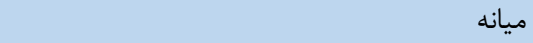 \\
\hline & $1 / r$ & $1 / 1$ & 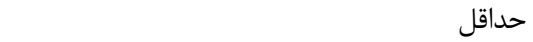 \\
\hline & r & IVD & 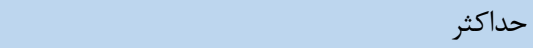 \\
\hline
\end{tabular}

* آزمون من - ويتنى

جدول ז: ميانگين و انحراف معيار سطح سرمى آنتىبادى هليكوباكتر קييلورى در گروه مورد و شاهد به تفكيك جنسيت

\begin{tabular}{|c|c|c|c|}
\hline \multirow[b]{2}{*}{ سطح معنادارى" } & \multicolumn{2}{|c|}{ تروه } & \multirow[b]{2}{*}{ جنسيت } \\
\hline & ميانَين شانحراف معيار & ميانگين土|نحراف معيار & \\
\hline$\cdot 10 \cdot 1$ & $\Gamma Y / T I \pm Y N / \wedge \varphi$ & $r \mid / D I \pm F V / F$. & مرد - \\
\hline$\cdot / \cdot \Delta \Delta$ & $r \Delta / \Lambda F \pm F r / G \varphi$ & $r \cdot / V \Lambda \pm r \cdot / 9 r$ & زن \\
\hline
\end{tabular}

* زن آزمون من-ويتنى 
جدول بّ: ميانكين و انحراف معيار آنتىبادى هليكوباكتر ييلورى در بيماران مبتلا به استروك بر حسب عوامل خطر آن

\begin{tabular}{|c|c|c|c|c|}
\hline \multirow[b]{2}{*}{ سطح معنادارى } & \multicolumn{2}{|c|}{ سابقه ابتلا } & \multirow[b]{2}{*}{ تعداد (نفر) } & \multirow[b]{2}{*}{ متغير } \\
\hline & 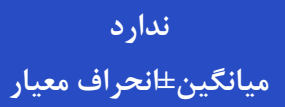 & 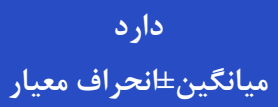 & & \\
\hline .1949 & $r \varepsilon / \varepsilon \Delta \pm r \Delta / I V$ & $\mid f / 9 V \pm 19 / \cdot 1$ & r & فشار خون \\
\hline . ITEV & $r q / \cdot r \pm r q / \cdot q$ & $19 / 11 \pm 19 / \mathrm{VV}$ & ir & ديابت \\
\hline$\cdot / \mu \cdot r$ & TI/TY $\pm F / A T$ & $\mid \varepsilon / r r \pm r \Delta / \Delta \Delta$ & 11 & بيمارى قلبى \\
\hline$\cdot \mid 1 \wedge 4$ & $r V / \Delta r \pm F \Delta / F \Delta$ & $r \mid / F \cdot \pm f l / \cdot q$ & M & آنزين ״كتوراليس \\
\hline . /TVq & $r \xi / \cdot q \pm F F / \cdot r$ & $r \Delta / T \Lambda \pm Y G / F T$ & 1. & MI \\
\hline - MFF & $r r / V \wedge \pm r \cdot / q$. & $V V / f \Delta \Delta \pm 1 \cdot r / \cdot 1$ & r & CABG \\
\hline$\cdot / r \wedge$ & $r G / F T \pm F F / T F$ & $1 / \wedge \cdot \pm \cdot / \cdot$. & 1 & آريتمى \\
\hline ( & $r r / \Delta q \pm r q / 4 q$ & $q \Gamma / 9 \cdot \pm 9 V / T^{4}$ & r & سابقه TIA \\
\hline .1 .91 & $r \wedge / \wedge \varepsilon \pm F \varepsilon / T$. & $f / 4 \varepsilon \pm r / v q$ & 4 & سابقه استروك قبلى \\
\hline - IDTq & T\&/ITEFF/AT & $F \Delta / r \mid \pm T r / F$. & r & TPA \\
\hline
\end{tabular}

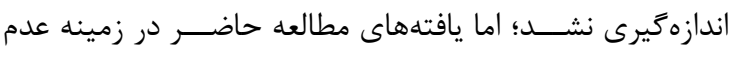

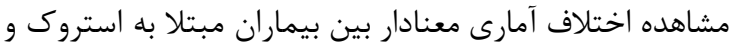

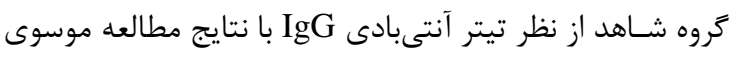
و همكاران همخوانى داشت.

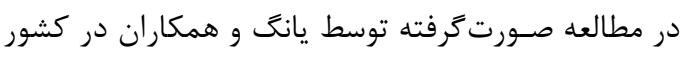

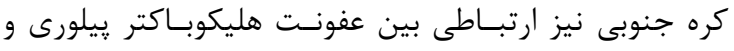

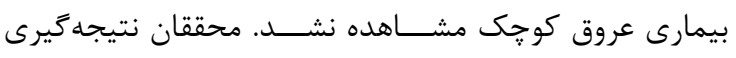

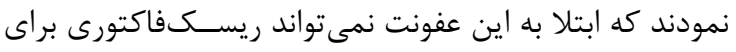

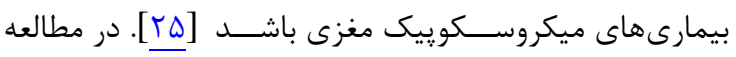

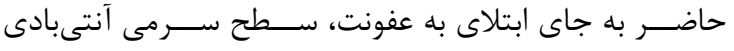

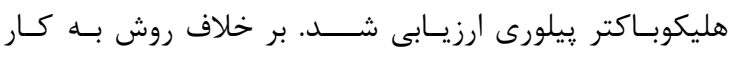

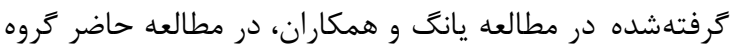

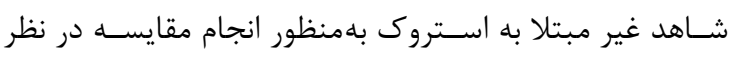

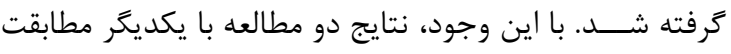
داشتند. در دو مطالعه ساعًار و همكاران در كشور هند [عب] و هانت

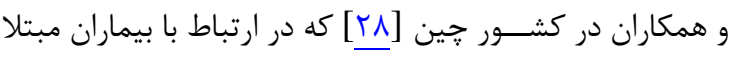

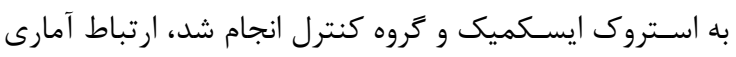

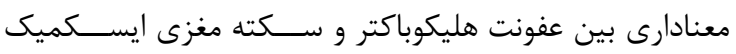

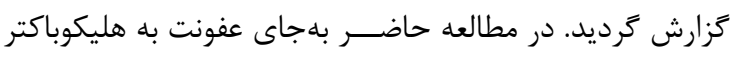

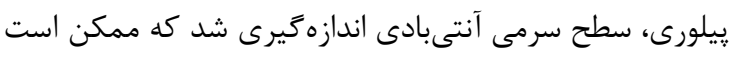

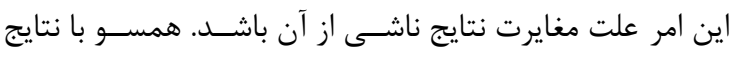

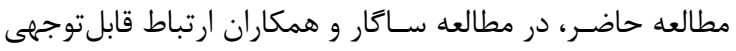

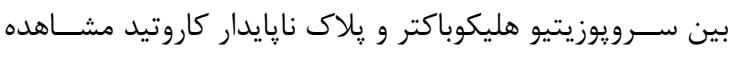

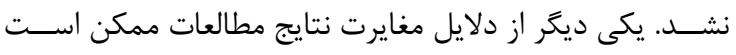

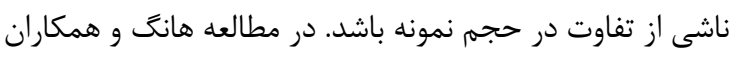

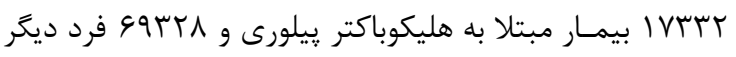

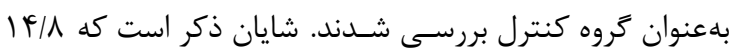

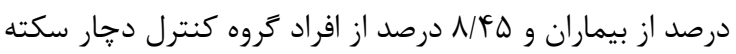
مغزى ايسكميك شدند.
بـا توجـهـ به جدول ب و نتايج آزمون نايارامترى من- ويتنى

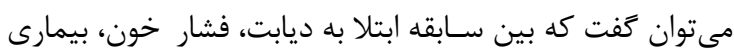

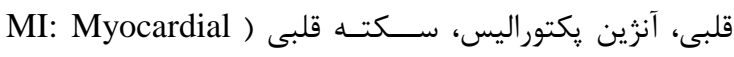

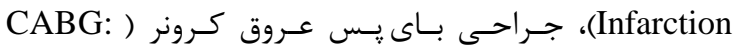
(Coronary Artery Bypass Grafting كذراى مغزى (TIA: Transient Ischemic Attack)، سـابقه

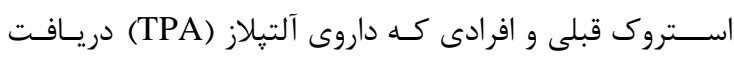

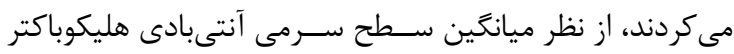
ييلورى تفاوت آمارى معنادارى وجود ندارد.

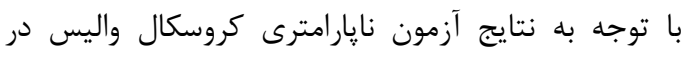

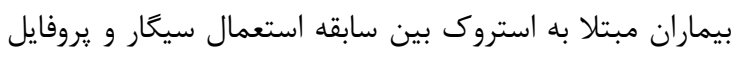
جربى غير نرمال با ميانكين سطح سرمى آنتىبادى هليكوباكتر ييلورى تفاوت آمارى معنادارى مشاهده نشد.

\section{بحث}

مهمترين يافته مطالعه حاضـــر اين بود كه ميانگين ســــح

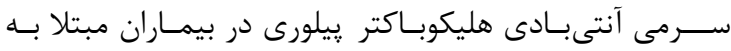
استروك كمتر از گروه شاهد غير مبتلا به استروك است.

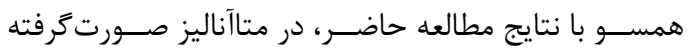

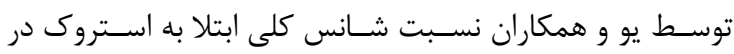

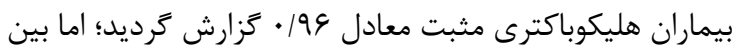

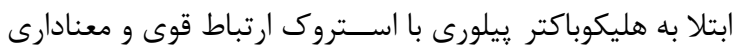
مشاهده نشد [1)] نتايج مطالعه انجامشده توسط موسوى و همكاران نيز حاكى

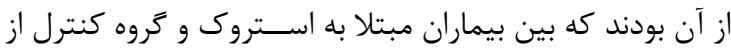

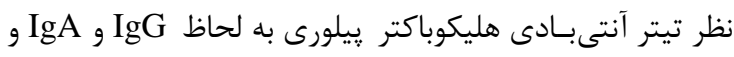

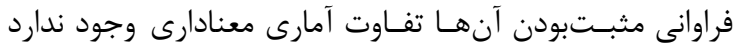

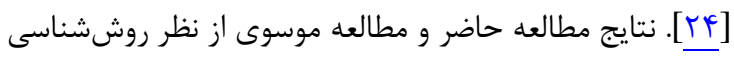

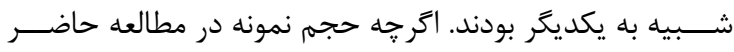

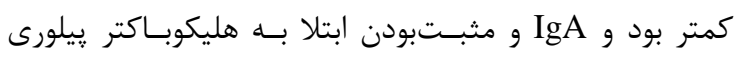




\section{تشكر و قدر دانى إنى}

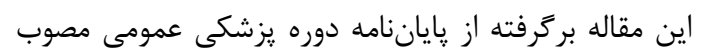

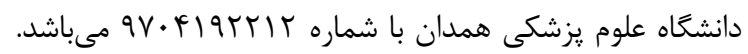

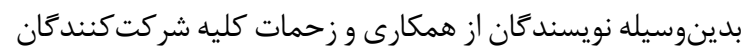
در طرح و كاركنان بخش نورولوزى بيمارستان فرشيحيان (سينا) همدان قدردانى مىنمايند.

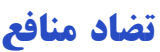

هيجَّونه تعارض منافعى در اين مطالعه كَارش نشده است.

\section{ملاحظات اخلاقي}

يزوهشــــران در تمـامى مراحل انجام اين مطالعه مقيد به

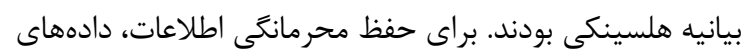

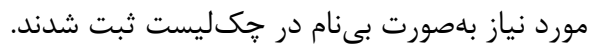

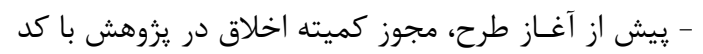

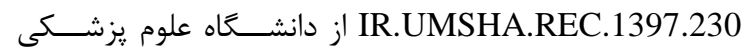

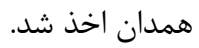

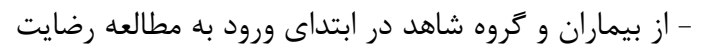

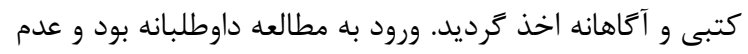
تمايل بيماران نسبت به شركت در مطالعه مانع اقدام درمانى آنها

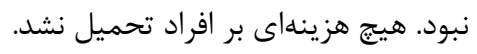

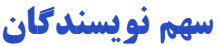

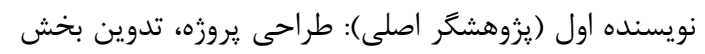

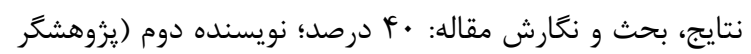

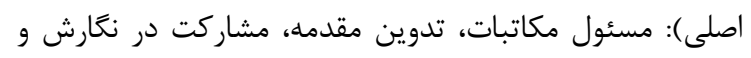
ويرايش مقاله: · · درصد؛ نويسنده سوم (ئزوهشكر همكار):

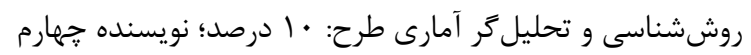

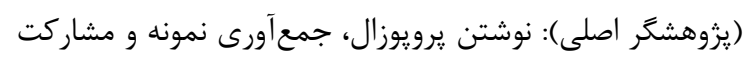
در تدوين نتايج: • إ درصد : نونشئ برو

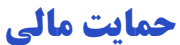

اين مطالعه از سوى معاونت تحقيقات و فناورى دانشخاه علوم

$$
\text { يزشكى همدان يشتيبانى مالى شده است. }
$$

\section{REFERENCES}

1. Menken M, Munsat TL, Toole JF. The global burden of disease study: implications for neurology. Arch Neurol. 2000;57(3):418-20. PMID: 10714674 DOI: 10.1001/ archneur.57.3.418

2. Ropper AH, Samuels MA. Adams, Victor's principles of neurology. $10^{\text {th }}$ ed. New York: McGraw-Hill; 2013.

3. Rowland LP, Pedley TA. Merritt's neurology. $12^{\text {th }}$ ed. Philadelphia: Lippincott Williams \& Wilkins; 2010.

4. Zock E, Kerkhoff H, Kleyweg RP, van Bavel-Ta TB, Scott S, Kruyt ND, et al. Help seeking behavior and onset-to-alarm time in patients with acute stroke: sub-study of the preventive antibiotics in stroke study. BMC Neurol. 2016;16(1):241. PMID: 27884126 DOI: 10.1186/s12883-016-0749-2

5. Khalid W, Rozi S, Ali TS, Azam I, Mullen MT, Illyas S, et
در دو يزوهش ديكر كـهـ توســـ بـاســتيانى و همكاران و

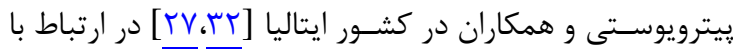

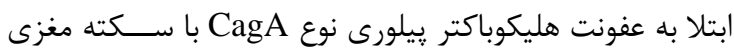

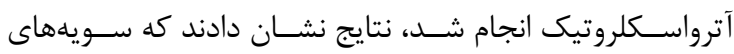
CagA

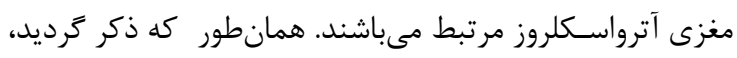

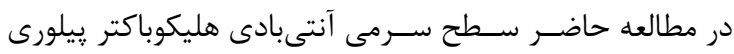

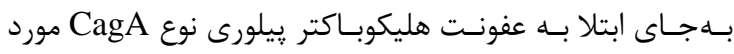

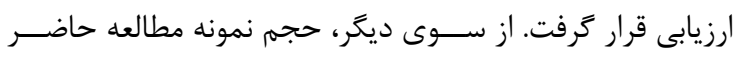

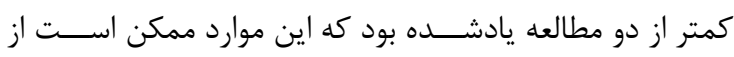
دلايل مغايرت نتايج مطالعات باشد.

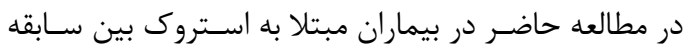

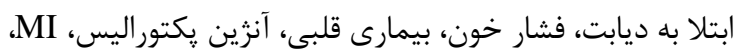
CABG

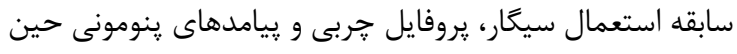

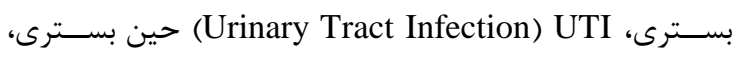
(Deep Vein Thrombosis) DVT

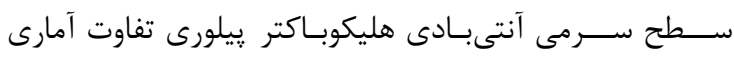

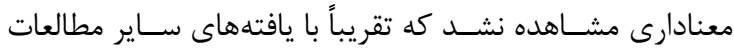

$$
\text { ذكرشده همسو مىباشد. }
$$

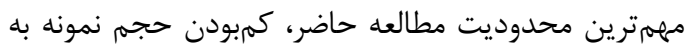

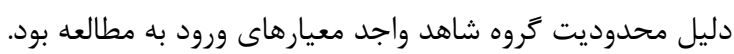

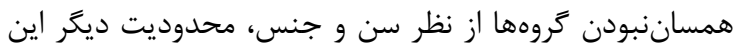

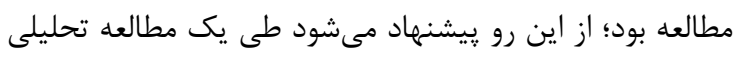

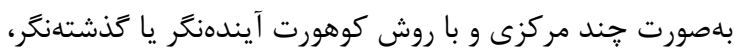

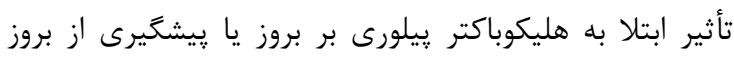

$$
\text { استروك مورد بررسى قرار گيرد. }
$$

\section{نتيجه تيرى}

در اين مطالعه سـطح سـرمى آنتىبادى هليكوباكتر ييلورى

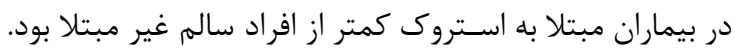

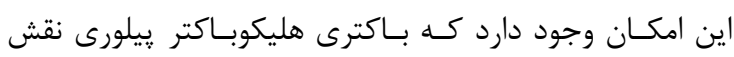

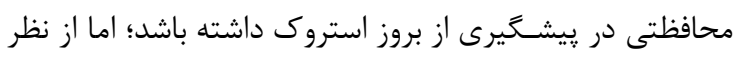
آمارى معنادار نمىباشد.

al. Quality of life after stroke in Pakistan. BMC Neurol. 2016;16(1):250. PMID: 27912744 DOI: 10.1186/s12883016-0774-1

6. Guzman Sabogal YR, Pla Vidal J, Sanchez Pedraza R, Ortuno Sanchez-Pedreno F, Gomez Guevara MC. Health-related quality of life in stroke patients questionnaire, short version (HRQOLISP-40): validation for its use in Colombia. BMC Neurol. 2016;16(1):246. PMID: 27894282 DOI: 10.1186/s12883-016-0770-5

7. Kotlega D, Bialecka M, Kurzawski M, Drozdzik M, Ciecwiez S, Golab-Janowska M, et al. Risk factors of stroke and 717A>G (rs2794521) CRP gene polymorphism among stroke patients in West Pomerania province of Poland. Neurol Neurochir Pol. 2014;48(1):30-4. PMID: 24636767 DOI: 
10.1016/j.pjnns.2013.12.001

8. Alkali N, Watt H, Bwala S, Gadzama A. Association of plasma homocysteine and ischemic stroke in Nigerian population. Pak J Med Sci. 2006;22(4):405-8.

9. Shoaeb MA, Shehata MA, Taema KM, Hammouda MA. CRP in cerebrovascular stroke: Prognostic implications. Egyp $J$ Crit Care Med. 2014;2(1):43-52. DOI: 10.1016/j.ejccm. 2014.03.001

10. de Kleijn MJ, van der Schouw YT, Verbeek AL, Peeters PH, Banga JD, van der Graaf Y. Endogenous estrogen exposure and cardiovascular mortality risk in postmenopausal women. Am J Epidemiol. 2002;155(4):339-45. PMID: 11836198 DOI: $10.1093 / \mathrm{aje} / 155.4 .339$

11. Price AJ, Wright FL, Green J, Balkwill A, Kan SW, Yang TO, et al. Differences in risk factors for 3 types of stroke: UK prospective study and meta-analyses. Neurology. 2018; 90(4):e298-306. PMID: 29321237 DOI: 10.1212/WNL. 0000000000004856

12. Ezzati M, Vander Hoorn S, Rodgers A, Lopez AD, Mathers $\mathrm{CD}$, Murray $\mathrm{CJ}$, et al. Estimates of global and regional potentil health gains from reducing muliple major risk factors. Lancet. 2003;362(9380):271-80. PMID: 12892956 DOI: $10.1016 / \mathrm{s} 0140-6736(03) 13968-2$

13. Meschia JF, Bushnell C, Boden-Albala B, Braun LT, Bravata DM, Chaturvedi S, et al. Guidelines for the primary prevention of stroke: a statement for healthcare professionals from the American heart association/American stroke association. Stroke. 2014;45(12):3754-832. PMID: 25355838 DOI: $10.1161 /$ STR.0000000000000046

14. Sacco RL, Adams R, Albers G, Alberts MJ, Benavente O, Furie K, et al. Guidelines for prevention of stroke in patients with ischemic stroke or transient ischemic attack: a statement for healthcare professionals from the American heart association/ American stroke association council on stroke: co-sponsored by the council on cardiovascular radiology and intervention: the American academy of neurology affirms the value of this guideline. Circulation. 2006;113(10):e409-49. PMID: 16534023

15. Andreoli TE, Fitz JG, Benjamin I, Griggs RC, Wing EJ. Andreoli and Carpenter's Cecil essentials of medicine Ebook: with student consult online access. New York: Elsevier Health Sciences; 2010. P. 416.

16. Mawanda F, Wallace R. Can infections cause Alzheimer's disease? Epidemiol Rev. 2013;35(1):161-80. PMID: 23349428 DOI: $10.1093 / \mathrm{epirev} / \mathrm{mxs} 007$

17. Elkind MS, Ramakrishnan P, Moon YP, Boden-Albala B, Liu $\mathrm{KM}$, Spitalnik SL, et al. Infectious burden and risk of stroke: the northern Manhattan study. Arch Neurol. 2010;67(1):33-8. PMID: 19901154 DOI: 10.1001/archneurol.2009.271

18. McColl BW, Allan SM, Rothwell NJ. Systemic infection, inflammation and acute ischemic stroke. Neuroscience. 2009;158(3):1049-61. PMID: 18789376 DOI: $10.1016 / j$. neuroscience.2008.08.019

19. Heuschmann PU, Neureiter D, Gesslein M, Craiovan B, Maass M, Faller G, et al. Association between infection with Helicobacter pylori and Chlamydia pneumoniae and risk of ischemic stroke subtypes: results from a population-based case-control study. Stroke. 2001;32(10):2253-8. PMID: 11588309 DOI: $10.1161 / \mathrm{hs} 1001.097096$

20. Sawayama Y, Ariyama I, Hamada M, Otaguro S, Machi T, Taira Y, et al. Association between chronic Helicobacter pylori infection and acute ischemic stroke: Fukuoka Harasanshin Atherosclerosis Trial (FHAT). Atherosclerosis. 2005;178(2):303-9. PMID: 15694938 DOI: 10.1016/j. atherosclerosis.2004.08.025

21. Su YP, Niu HW, Chen JB, Fu YH, Xiao GB, Sun QF. Radiation dose in the thyroid and the thyroid cancer risk attributable to CT scans for pediatric patients in one general hospital of China. Int J Environ Res Public Health. 2014;11(3):2793-803. PMID: 24608902 DOI: 10.3390/ ijerph110302793

22. Mozaffarian D, Benjamin E, Go A, Arnett D, Blaha M, Cushman M, et al. Heart disease and stroke statistics-2015 update: a report from the American heart association. Circulation. 2015;131(4):e29-322. PMID: 25520374 DOI: 10.1161/CIR.0000000000000152

23. Ameriso SF, Fridman EA, Leiguarda RC, Sevlever GE. Detection of Helicobacter pylori in human carotid atherosclerotic plaque. Stroke Dallas. 2001;32(2):385-9.

24. Mousavi SA, Ataei B, Karimi I, Ashrafi K. Helicobacter pylori serum antibody titers in patients with cerebral noncardioembolic ischemic stroke. J Res Med Sci. 2011; 16(Suppl 1):S407-11. PMID: 22247726

25. Jang SH, Lee H, Kim JS, Park HJ, Jeong SM, Lee SH, et al. Association between helicobacter pylori infection and cerebral small vessel disease. Korean J Fam Med. 2015; 36(5):227-32. PMID: 26435813 DOI: $10.4082 / \mathrm{kjfm} .2015$. $\underline{36.5 .227}$

26. Sagar V, Zafar KS, Kumar G, Veeramachaneni R, Indurkar PS. A study of Helicobacter pylori infection in patients of ischemic cerebro vascular stroke. Int J Res Med Sci. 2016;4:589-92. DOI: 10.18203/2320-6012.ijrms20160321

27. Pietroiusti A, Diomedi M, Silvestrini M, Cupini LM, Luzzi I, Gomez-Miguel MJ, et al. Cytotoxin-associated gene-A-positive Helicobacter pylori strains are associated with atherosclerotic stroke. Circulation. 2002;106(5):580-4. PMID: 12147540 DOI: 10.1161/01.cir.0000023894.10871.2f

28. Huang WS, Tseng $\mathrm{CH}$, Lin $\mathrm{CL}$, Tsai $\mathrm{CH}$, Kao $\mathrm{CH}$. Helicobacter pylori infection increases subsequent ischemic stroke risk: a nationwide population-based retrospective cohort study. QJM. 2014;107(12):969-75. PMID: 24890556 DOI: 10.1093/qjmed/hcu117

29. Russo F, Jirillo E, Clemente C, Messa C, Chiloiro M, Riezzo $\mathrm{G}$, et al. Circulating cytokines and gastrin levels in asymptomatic subjects infected by Helicobacter pylori $(H$. pylori). Immunopharmacol Immunotoxicol. 2001;23(1):1324. PMID: 11322645 DOI: 10.1081/iph-100102563

30. Xue FB, Xu YY, Wan Y, Pan BR, Ren J, Fan DM. Association of $H$. pylori infection with gastric carcinoma: a Meta analysis. World J Gastroenterol. 2001;7(6):801-4. PMID: 11854905 DOI: 10.3748/wjg.v7.i6.801

31. Yu M, Zhang Y, Yang Z, Ding J, Xie C, Lu N. Association between Helicobacter pylori infection and stroke: a metaanalysis of prospective observational studies. J Stroke Cerebrovasc Dis. 2014;23(9):2233-9. PMID: 25263434 DOI: 10.1016/j.jstrokecerebrovasdis.2014.04.020

32. De Bastiani R, Gabrielli M, Ubaldi E, Benedetto E, Sanna G, Cottone $\mathrm{C}$, et al. High prevalence of Cag-A positive $H$. pylori strains in ischemic stroke: a primary care multicenter study. Helicobacter. 2008;13(4):274-7. PMID: 18665936 DOI: 10.1111/j.1523-5378.2008.00610.x 